\title{
As consequências da busca norte-americana pela primazia nuclear
}

The consequences of the North American search for nuclear primacy

Cristhofer Weiland ${ }^{1}$

\section{RESUMO}

Este artigo tem, como objetivo, através de uma breve análise quanto à primazia nuclear dos Estados Unidos no imediato pós-Segunda Guerra Mundial, da balança de poder estabelecida durante a Guerra Fria e da Doutrina da destruição mútua assegurada (MAD), apresentar a nova busca norte-americana pela primazia nuclear e suas consequências perante a MAD. A principal conclusão percebida é a de que o sistema internacional, nos próximos anos, tornar-se-á multipolar.

Palavras-chave: Primazia Nuclear; Estados Unidos; Destruição Mútua Assegurada

\begin{abstract}
This paper has, as objective, through a brief analysis about the United States' nuclear primacy in the immediate post-World War II, of the balance of power established during the Cold War and of the doctrine of Mutual Assured Destruction (MAD), to present the North American new search for nuclear primacy and its consequences before MAD. The perceived main conclusion is that the international system, in years ahead, will become multipolar.
\end{abstract}

Key-words: Nuclear Primacy; United States; Mutual Assured Destruction

\section{Introdução}

A partir do fim da Segunda Guerra Mundial, os Estados Unidos usufruíram de poder de barganha estabelecido através da "primazia nuclear" (a distribuição de poder no sistema internacional dava-se por meio do poder nuclear), que fez com que a União Soviética, única potência capaz de fazer frente aos EUA, entrasse em uma corrida armamentista com os norte-americanos.

Em um primeiro momento, é feita uma breve análise quanto à primazia nuclear norte-americana logo após o fim da Segunda Guerra Mundial, da balança de poder estabelecida entre os Estados Unidos e a União Soviética durante a Guerra Fria e a Doutrina da Destruição Mútua Assegurada (Mutual Assured Destruction - MAD). Com

\footnotetext{
${ }^{1}$ Pós-Graduando do Curso de Especialização em Estratégia e Relações Internacionais Contemporâneas pela Universidade Federal do Rio Grande do Sul (UFRGS). Bacharel em Relações Internacionais pela Universidade de Santa Cruz do Sul (UNISC).
} 
esta breve análise feita, entra-se, então, no objetivo deste artigo: apresentar a nova busca dos norte-americanos pela primazia nuclear e as consequências disto em confronto com a MAD.

Para tanto, será utilizado, neste artigo, o método analítico, explorando o assunto através de fontes bibliográficas, sendo, principalmente, utilizados os artigos científicos dos autores Lieber e Press (2006 e 2007) e Ávila, Martins e Cepik (2009).

\section{Primazia Nuclear, Guerra Fria e Destruição Mútua Assegurada}

Após o fim da Segunda Guerra Mundial, os Estados Unidos, através da corrida armamentista e do desenvolvimento de armas nucleares, logo nos primeiros anos da Guerra Fria, atingiram um patamar o qual os estudiosos denominam de "primazia nuclear". Entende-se, por primazia nuclear, a incapacidade de um adversário responder a um ataque nuclear com outro (ÁVILA; MARTINS; CEPIK, 2009).

Com o fim da Segunda Guerra Mundial, a União Soviética era a única potência capaz de rivalizar com os EUA e, devido às divergências ideológicas, desencadeou uma polarização do sistema internacional entre estes Estados. Mas esta bipolarização estava longe de ser equilibrada, pois os Estados Unidos eram muito superiores a URSS. Tanto no âmbito militar, quanto em questões de economia e política (ALBUQUERQUE, 2007).

Ao início dos anos de 1960, os soviéticos também desenvolveram armas nucleares e levaram a guerra a um novo estágio no qual nem os EUA nem a URSS conseguiriam destruir, totalmente, o outro, de modo a evitar um ataque retaliatório, mesmo que o primeiro ataque fosse surpresa. Este impasse militar é conhecido como "Destruição Mútua Assegurada (MAD)" e foi combatido durante a Guerra Fria pelos Estados Unidos de modo a reestabelecer sua supremacia nuclear (LIEBER; PRESS, 2006).

Deste modo, ao invés do planejamento para uma guerra vitoriosa, o máximo que poderia ser feito eram simulações da guerra, ou seja, uma dissuasão que fosse convincente para que se evitasse o início de um conflito imensurável (MARQUES, 2005). "Por dissuasão, entenda-se a ameaça explícita e crível de que um ataque será respondido com uma retaliação tão pesada a ponto de tornar o custo de um primeiro ataque muito maior do que quaisquer benefícios que dele poderiam advir" (ÁVILA; MARTINS; CEPIK, 
2009, p. 51). Todavia, contrariando a ideia de que as armas não podem ser utilizadas limitando-as à dissuasão, em momentos de tensão real, o uso do armamento atômico foi ponderado e, até mesmo, autorizado - relembrando, brevemente, os casos do Reservatório de Chosin² e da Ilha Quemoy³ (MOITA, 2007).

A balança de poder no sistema internacional se estabeleceu, durante o período de Guerra Fria, de acordo com a posse de armamentos nucleares e pela capacidade de ter um segundo ataque retaliatório. Assim como neste período e, até os dias de hoje, essa capacidade de resposta dos Estados Unidos a um primeiro ataque é permitida através de um tripé operacional que consiste em bombardeiros estratégicos, mísseis balísticos intercontinentais (conhecido pela sigla ICBM) e submarinos lançadores de mísseis balísticos (SLBM). É claro que, com a digitalização e a emergência de novos tipos de armas, quanto mais letais elas se tornam, mais exigentes se tornam as contramedidas de dissuasão e de capacidade de defesa proficiente (ÁVILA; MARTINS; CEPIK, 2009).

Essa corrida armamentista entre os EUA e a URSS atingiu, em seu ápice, o expressivo número de mais de 70 mil ogivas nucleares no ano de 1986. Apesar disto, este número vem caindo devido ao fim da Guerra Fria e a crescente sofisticação e diminuição no tamanho dos armamentos e, ainda assim, aumentando a periculosidade, de modo a serem desnecessárias enormes quantidades se comparadas as de tecnologia obsoleta (MOITA, 2007). Esta busca por aprimoramento acabou se tornando um dos principais fatores que levaram ao fim da União Soviética, que não dispunha de uma economia muito forte e nem da tecnologia para acompanhar os EUA - como já anteriormente exposto. Sendo assim, necessitavam de muitas ogivas para compensar a sofisticação dos mísseis estadunidenses.

Com o fim da Guerra Fria, os EUA aprimoraram ainda mais o seu arsenal, substituindo seus mísseis balísticos por outros mais qualificados. Enquanto isso, o arsenal estratégico da Rússia ${ }^{4}$ se deteriorava demasiadamente e isso não significa que

\footnotetext{
2 Em 1950, quando os marines americanos ficaram cercados por tropas chinesas no Reservatório de Chosin, na Coreia do Sul, o presidente Truman anunciou que encarava a utilização de armamento nuclear (MOITA, 2007).

${ }^{3}$ Caso no qual, em 1958, o presidente Eisenhower havia autorizado secretamente a utilização de armas nucleares contra a China em situação de invasão da Ilha de Quemoy (MOITA, 2007).

${ }^{4}$ Com o fim da URSS, a Rússia ficou como herdeira de todo armamento nuclear, enquanto todas as outras 14 antigas repúblicas soviéticas assinaram o Tratado de Não-Proliferação de Armas Nucleares (TNP), deixando a Rússia em segundo lugar como potência nuclear (GASPAR, 2011).
} 
um ataque preventivo norte-americano daria certo, nem que, de fato, haveria um ataque dos EUA, mas o que é sugerido é o fato de que, se não houvesse o desmantelamento da URSS, a vulnerabilidade só aumentaria (LIEBER; PRESS, 2006). Isto caracterizava o início do fim da MAD e apenas os primeiros "frutos colhidos" de uma nova era que levaria os Estados Unidos, novamente, à primazia nuclear (LIEBER; PRESS, 2007).

\section{A busca pela nova Primazia Nuclear Norte Americana e suas consequências}

Esta projeção em torno de uma nova primazia norte-americana foi baseada nas avaliações quanto às capacidades de segundo ataque tanto da Rússia, quanto da emergente China ${ }^{5}$ (ÁVILA; MARTINS; CEPIK, 2009). Com um ataque surpresa, os EUA teriam boas chances de destruir todo tripé nuclear russo. Quanto à China, seu arsenal nuclear é ainda mais frágil e, um primeiro ataque norte-americano, obteria sucesso sendo surpresa ou até mesmo em meio a uma crise, onde os chineses estariam em alerta (LIEBER; PRESS, 2006). Os Estados Unidos possuem um planejamento que é um luxo para poucos países, qual seja a sua capacidade bélica de poder considerar alvos prováveis como alvos reais e, assim, poder destruir com todas as possibilidades - e isto pode considerar-se uma vantagem dos EUA sobre a China (LIEBER; PRESS, 2007).

"Os EUA buscam abertamente a primazia em todas as dimensões das tecnologias militares modernas, tanto em seu arsenal convencional como em suas forças nucleares"6 (LIEBER; PRESS, 2006, p. 52). Eles preferem a ideia de, no futuro, encarar uma guerra utilizando-se de armas convencionais, mesmo contra adversários que possuem armas nucleares. Assim, podem aproveitar-se do benefício da primazia para dissuadir seus adversários a não usarem suas armas nucleares (LIEBER; PRESS, 2007). A primazia também pode ser até uma alternativa à guerra: a sua busca, conforme Huntington (1993), citado por Guimarães (2002), além de manter a própria segurança, ocorre para promover os interesses do Estado, estipulando e implementando os seus valores no sistema internacional, sendo, assim, uma alternativa à guerra.

Historicamente, o sistema internacional alternou sua polarização entre momentos de primazia nuclear e o retorno da destruição mútua assegurada, sendo esta

\footnotetext{
${ }^{5}$ Desde 1991, a China - assim como a França - foi admitida como Estado nuclear no TNP, reforçando sua capacidade e eficácia (GASPAR, 2011).

${ }^{6}$ Tradução livre.
} 
uma estratégia de necessidade. A única opção disponível além da MAD seria a primazia nuclear norte-americana, porém a Rússia não aceitaria esta condição e buscaria novamente a paridade, levando sempre a condição de destruição mútua assegurada (SAFRANCHUK, 2006).

Atualmente, no sistema internacional, pode-se analisar a entrada de um novo participante nesta corrida pela primazia nuclear: a China. De acordo com Bao (2007), se houver o desenvolvimento de uma nova arma pelo adversário e ele estiver preparado para utilizar esta tecnologia, o Estado Chinês também tentará desenvolver esta arma. Porém, a China nunca buscará a realização de um primeiro ataque ou assumirá postura ofensiva, mas utilizará todos seus esforços para evitar um ataque adversário. Portanto, se a China possuir armas espaciais, assim como qualquer outro tipo de armas, estas serão limitadas à quantidade e qualidade estritamente necessárias para a defesa efetiva e não para o ataque contra outros países, diferentemente dos EUA e da Rússia.

Essas estratégias são corroboradas por ações chinesas: as diversas capacidades militares que a China está desenvolvendo se refletem em operações de anti-acesso e negação de área (em inglês, anti-acess and area-denial (A2/AD)), ou seja, estratégias de defesa (TOL, 2010). Este conjunto de estratégias busca causar dano em seu adversário que seja mais custoso à tentativa do ataque, causando danos nos sistemas internos de submarinos e aviões (que funcionam através sistemas informatizados), fazendo-os retornar para a base.

Assim, é esta busca pela primazia por parte dos EUA que acaba servindo como acelerador do armamento convencional tanto da China quanto da Rússia. Deste modo, alcançar a primazia nuclear "pode ser um grande desapontamento estratégico" (SAFRANCHUK, 2006, p. 92), tornando a sua busca um desperdício de investimentos aplicados à causa. Então, mesmo que a supremacia nuclear virasse realidade, isto seria insuficiente para manter uma distribuição de poder unipolar. A militarização do espaço faz com que os russos e chineses busquem capacidades de mesmo quilate (da forma que se mostre possível para eles) e todos estes fatores ajudam a consolidar a multipolaridade do sistema internacional (ÁVILA; MARTINS; CEPIK, 2009).

A capacidade de lutar uma guerra nuclear continua fazendo parte da doutrina militar estadunidense e a busca pela primazia nuclear permanece sendo um dos seus 
objetivos (LIEBER; PRESS, 2006). Portanto, desde o fim da Segunda Guerra Mundial, "os dilemas da revolução nuclear permanecem intactos. As armas nucleares continuam a ser um instrumento crucial para a segurança das potências internacionais e para a balança do poder" (GASPAR, 2011, p. 103).

\section{Considerações Finais}

Pôde haver um período entre o fim da Guerra Fria e os dias atuais em que os EUA estiveram próximos de possuírem a primazia nuclear. Mas, historicamente, o sistema internacional alternou sua polarização entre momentos de primazia nuclear e o retorno da destruição mútua assegurada. Hoje em dia, esta busca pela primazia, por parte dos Estados Unidos, possui margem pequena de vantagem, devido aos revides de gastos empenhados por Rússia e China, o que acabará estabelecendo, em poucos anos, um sistema internacional predominantemente multipolar.

A Rússia e a China acabam por estabelecer e investir em sua força militar de maneira defensiva, pois a finalidade de ambos (devido às diferenças de emprego de investimento nesta área) não é ganhar, mas sim tornar a vitória para os Estados Unidos algo insustentável. É muito menos custoso se mobilizar para a defesa, pois o ofensivo arca com despesas como combustível para o deslocamento de tropas e comida para mantê-las. Esta é a maior força de dissuasão da Rússia e da China, com os tipos de investimento em $\mathrm{A} 2 / \mathrm{AD}$, uma eventual primazia nuclear norte-americana acaba por se tornar meros números, pois a ideia não é destruir as forças estadunidenses, mas sim fazê-la ir embora, ou seja, tornar o ataque algo com mais prejuízos do que benefícios.

Mesmo assim, 65 anos após o bombardeio norte-americano das cidades japonesas de Hiroshima e Nagasaki, as armas nucleares continuam a ditar a segurança das potências internacionais, assim como o equilíbrio na balança de poder e a busca por primazia nuclear continua sendo importante para os Estados Unidos, que esperam obter benefícios como o poder de dissuasão e a possibilidade de se utilizar de meios tradicionais de guerra contra países que detém armas nucleares. 


\section{Referências Bibliográficas}

ALBUQUERQUE, José Augusto Guilhon. Relações Internacionais Contemporâneas: a ordem mundial depois da Guerra Fria. Petrópolis: Vozes, 2007.

ÁVILA, Fabrício Schiavo; MARTINS, José Miguel; CEPIK, Marco. Armas estratégicas e Poder no Sistema Internacional: O Advento das Armas de Energia Direta e seu Impacto Potencial sobre a Guerra e a distribuição Multipolar de Capacidades. Contexto Internacional, Rio de Janeiro, v. 31, n. 1, p. 49-83, abr. 2009.

BA0, Shixiu. Deterrence Revisited: Outer Space. China Security, p. 2-11, winter 2007.

GASPAR, Carlos. 0 regime de não-proliferação nuclear. Janus [online], v. 15, n. 1, p. 102103, 2011.

GUIMARÃES, Cesar. A política externa dos Estados Unidos: da primazia ao extremismo. Estudos Avançados [online], v. 16, n. 46, p. 53-67, 2002.

LIEBER, Keir A.; PRESS, Daryl G. U.S. Nuclear Primacy and the Future of the Chinese Deterrent. China Security, p. 66-89, winter 2007. . The Rise of US Nuclear Primacy. Foreign Affairs, v. 85, n. 2, p. 42-54, mar./apr. 2006.

MARQUES, Viriato Soromenho. Violência e poder nas relações internacionais. Janus [online], v. 9, n. 1, p. 2-7, 2005.

MOITA, Luís. 0 armamento nuclear do mundo. Janus [online], v. 11, n. 1, p. 2-7, 2007.

SAFRANCHUK, Ivan. Beyond the MAD. China Security, p. 90-98, autumn 2006.

TOL, J. V. et al. Air Sea Battle. Washington: Center for Strategic and Budgetary Assessments, 2010. 